\title{
Viewpoint: Engagement in local social-ecological knowledge practices in a seasonal cycles approach for transitioning to future sustainability
}

\author{
Rob O’Donoghue, Rhodes University, South Africa
}

\begin{abstract}
This paper explores climate as variable natural forces driving seasonal cycles ${ }^{1}$ that many African cultures had adjusted themselves to within intergenerational knowledge practices of longue durée. The study points to the need to re-orientate and expand climate science education so that it is centred on the seasonal cycles and intergenerational learning to better align transitioning to future sustainability with these in our southern African contexts of climate change today. The narrative touches upon historical accounts of knowledge practices amongst the Krobo, Bemba, Shona, Zulu and Xhosa, briefly pointing to how each, as an African culture, is situated as a social-ecological entity within the climatic tapestries of our African landscapes. It takes note of how cultural articulation within the seasonal cycles of regional climate have a long history with adaptive change in some contexts in more recent times. The review suggests that our learning in relation to emerging climate change should be informed by these histories of intergenerational knowledge practice. It notes how a better grasp of these could be important drivers of a widening cultural response to the changing dynamics in our climatic surroundings today. The brief study suggests that southern Africa is a special place with many unique and interesting climatic processes and associated socio-ecological systems and practices. These can provide engaging perspectives for informing education to mitigate or adapt to climate change. Here, a situated exploration of seasonal cycles can draw on both the latest in modern climate science and the rich social-ecological heritage of Africa briefly touched upon in the study. A model of process is offered for how both can be used in a seasonal cycles approach climate change education. This better situated and more inclusive approach can enable us to contemplate how we might best adjust our social-ecological dispositions and practices in the changing world that we all share.
\end{abstract}

\section{Preamble}

The current proliferation of education imperatives responding to climate change might be described as colonising disruptions of everyday life where convincing messages convey complex ideas for citizens to become aware of the problem and to confront the prospect of fearful futures unless they can change themselves and the fabric of modern society. Here, communicating knowledge to create awareness, learning and change has been surprisingly ineffective as people appear to become aware of the problem but change towards more sustainable futures is seldom evident or lasting.

This study examines this problem in an African context to contemplate how an effective climate education programme is managing to work with historical evidence. This is necessary to communicate climate science in ways that enable participants to situate patterns of climate change in their context. In this way, networking communities of civic scientists might best 
align their futures within the dynamics of the seasonal cycles in their region (see O'Donoghue, Kibuka-Sebitosi, Tshiningayamwe \& Palmer (2019), this edition). A seasonal cycles approach in education adds two missing dimensions to current communications. Firstly, the messages are redirected to meaning-making in community and in relation to seasonal cycles, and secondly, these are culturally situated being derived from, and related to, the social-ecological practices of earlier times in the region.

\section{Background}

A colonial image of African ignorance has long been overturned by researchers who have revealed a sense of the depth and wisdom in many of the indigenous knowledge practices and cultural responses to climatic variation amongst African peoples. This is still not widely known as most scientific discourses on climate change make little or no reference to heritage knowledge practices or to some of the wisdom in many African intergenerational responses to the seasonal cycles and associated climatic variation in central and southern Africa. It would be interesting to explore how the cultural capital examined in this brief study might be used alongside scientific models of process and to situate, understand and mitigate some of the adverse effects of an anticipated expansion of climate extremes in southern African regions.

In this paper, I briefly sketch some historical evidence of the contours of knowledge on climate and climate variation that are etched in pre-colonial African landscapes and within the cultural heritage of many intergenerational knowledge practices. I have learned of these through the educational fieldwork that I have undertaken with many of my students over the last decade and in my work on Environment and Sustainability Education (ESD) and climate change education at the Environmental Learning Research Centre, Rhodes University. My intention is to challenge and expand on some of the current approaches to climate change education by simply pointing to some gaps that need attention. The paper suggests that African scholars and researchers can make an important contribution to climate science by contemplating the social-ecological heritage of Africa and the knowledge practices of indigenous peoples, many of whom are struggling with harsh conditions of increasing climate variation today.

Through this study, I hope to convey a hopeful sense of how southern Africa is a special place and how our peoples and landscapes hold an exciting social-ecological capital for learning to adjust to the climatic challenges in a changing world today.

\section{Evidence of early African social-ecological adjustment within seasonal cycles}

Many scientists find it hard to imagine that earlier societies developed climate forecasting and managed to do so with some success in areas that had fairly predictable seasonal cycles. The climate sciences are much advanced today, but our seasonal forecasting still lacks sufficient accuracy to be wholly reliable. It is not surprising that scientists remain trapped in the reductionist disposition that they know more and better than those who came before them. Many have thus given little attention to African cultural and climatic histories and the intergenerational socio-cultural adjustments in Africa are seldom used to deliberate global 
change induced variation in seasonal cycles and to inform future sustainability.

The brief overview of some historical cases of climate related socio-cultural alignment within seasonal cycles opens in one of the most stable climatic systems, the Inter-tropical convergence zone (ITCZ). I learned at school how the ITCZ migrates seasonally with the sun in tropical central Africa bringing warm, wet and cool, dry seasons.

\section{Krobo seasonal cycle of tillage (Ghana)}

Norbert Elias, a cultural sociologist, noted how 'seasonal timing' in the agrarian society of the Krobo of Ghana was mediated by tribal 'priests'. Referring to this, Johan Goudsblom (1989) points out how the seasonal calendar available to people is constituted as a sociocultural capital that was commonly entrusted to priests in early agrarian societies. Here the cooperation involved in seasonal timing was constituted in a social capital of knowledge as '[p] eople always remained dependent upon sun, wind and rain - natural forces over which they could exert no control but to which they could try to adjust themselves to the best of their knowledge' (1989:75).

The spiritual leaders of the Krobo in one area of Ghana are said to have mediated the seasonal cycle of tilling and planting by tracking the movement of the sun until it rose to shine through a crack in the rocks of a hillside. This cyclical process was read alongside an associated building of rain-bearing clouds and all of the villagers waited for the instruction that the season for planting had arrived and they could all go out to till their lands.

\section{Bemba socio-cultural cycles in chitemene and fundikila (Zambia)}

Chitemene agriculture in the Miombo woodlands of Zambia (see Shumba \& Kalaba, in O’Donoghue, Sandoval Rivera \& Payyappallimana, this edition) is a good example of a sociocultural process involving similar seasonal timing in a similarly stable high rainfall climatic area. This socio-cultural system has patterns of cultural mediation that extended to a cyclical process of around two decades. One thus not only had the seasonal activities of around five years for the slash and burn tilling of a home area where children were born but an extension of this to around 15 to 20 years. Here, for the young to marry, they had to return to the lands of their birth, thereby enacting an extended fallow period for the forest to recover. This cultural cycle served to restore the ecological consequences of the slash and burn agricultural process that not only effected nutrient transfer from biomass to crop in leached forest soils, but also served to control soil pests with heat and smoke associated with the seasonal burning of arable land before planting with the arrival of the rains. Local farmers in Zambia have noted how the rains coming from the southern migration of the ITCZ from the north often give some early rains to enable ploughing but then, about a month later, daily afternoon rains make it difficult to work the land. The emerging pattern today is that things are more uncertain and that the growing season is now shorter with the first rains now appearing two to three weeks later in the expected seasonal cycle in central Zambia.

In recent history, as the numbers of people increased and the forested areas shrank, a fundikila system of agriculture developed in more and more areas as an adaptation of the earlier chitemene (Matthews, Holden, Volk \& Lungu, 1992). This included seasonal variation in cropping that is 
now at the heart of the hybrid system that one finds in the same climatic region today as the onset of the summer season rains is now commonly offset into December. Each successive adaptation has evolved to feed larger populations on the same resource base, but some of the early forest system is now fragmented and at risk.

\section{Mashona seasonal cycle and the Mkuvisi landscape (Zimbabwe)}

Similar long-term patterns of socio-ecological livelihood practices are found in the more southern Mkuvisi woodland communities of central and northern Zimbabwe. This served not only to shape the landscape over decades of seasonal shifting agriculture, but to develop seasonal patterns of grazing that were supported by the predominately leguminous trees that fix nitrogen to support the nutritious grasses needed by the Mashona cattle. Here the impact of climatic uncertainty in a climatic region of greater seasonal variation was mitigated by the cultural pattern of agro-forestry that people had adjusted to over many generations until this was disrupted by the colonial intrusion. (See Shava \& Masuku in this edition.)

\section{Zulu cycles of hunting and driving (KwaZulu-Natal, South Africa)}

Moving south and east in southern Africa one finds the Zululand grasslands that were similarly expanded through the cultural patters of fire use to create pasture commonage and to keep the Nagana cattle disease at bay. Here the cultural shaping of the landscape was less driven by seasonal cycles and more by burning as a response to seasonal change and outbreaks of the Nagana cattle disease associated with the tsetse fly. (See Masuku, in O'Donoghue, Sandoval Rivera \& Payyappallimana, this edition.)

\section{Xhosa seasonal migration (Eastern Cape, South Africa)}

It is only when one gets further south to the sweet veld grasses of the Xhosa that one finds cultural patterns of seasonal practice in response to more extreme climate variation. This part of southern Africa is an areas of very high climate variation driven by its position in southern Africa at the boundaries of three climatic systems, the Southern Ocean, the southern Indian Ocean and the central African ITCZ. As a boundary space the peoples were subject to high seasonal variability that are now only slightly easier to predict as scientists like George Philander have been able to uncover the working of the El-Nino-La-Nina oscillation in the southern Pacific and how this impacts on the climate of southern Africa and elsewhere.

Using fire in a similar way to the Zulu and Shona, but in a different way to the peoples of northern Zambia, the Xhosa were able to maintain their sweet veld grasses in all but the episodic dry summer seasons. They thus had to adjust themselves in other ways, two of which are notable: (1) seasonal migration to and from the Zuurveld in the south; and (2) Galesha (explained below) at the turn of the winter season.

Seasonal migration was not unlike the transhumance of north Africa and the European Alps and other mountainous regions of the world in some ways, but it was more driven by seasonal variation.

Galesha is a particular seasonal cycle/climate variation adaptation that has all but disappeared amongst Xhosa farmers owing to the financial costs of preparing the land for the ingress of 
water at the end of the cropping season. As Orion's Belt becomes visible in the early winter night sky, farmers would put their cattle into the harvested fields and then plough the soil that had been broken up by the cattle's hooves, turning in the remaining dung, chaff and dry weeds. Denison and Wotshela (2009) describe how this loosening of the soil would allow the light winter rains to be retained in the soil as a rainwater harvesting practice for the coming cropping season. The deeper explanation was, however, more practical, namely that if the rains were late to arrive in a dry season, the pastures would be poor and the cattle weak so they would have to be moved away to the Zuurveld and those remaining to plough would not have the strength to prepare the lands for the summer crops.

Throughout Africa, there are many such narratives that reflect a competency in living within both the usually predictable or highly variable climatic patterns that characterise the socialecological landscapes and seasonal cycles of Africa.

\section{Decolonising as a situated process of intergenerational learning}

As indicated earlier, the above examples are surface stories out of the historical record of the region or in the fabric of rural memories that can be useful to guide action and learning-led change. The historical abstractions and summaries of narrative experiences have been mapped out on these pages to simply point to the richness in the socio-ecological cycles of African peoples on the landscapes of Africa that reflect cultural responses within diverse seasonal cycles. The danger of becoming informed in this way is that the knowledge practices of each of the illustrative cases are not abstract propositions, but are etched in local landscape and seasonal practices mediated within local social structures in Mother Tongue. We cannot simply share narrative accounts of these as has been the colonial education practice.

The Habitable Planet initiative of the CSIR ACCESS programme is notable for an expansion of climate education to the inclusion of the rich heritage and landscapes as these are shaped within the seasonal cycles of history and contemporary society. Its opening strength was the coherent way in which Earth science knowledge was conveyed by inspiring young scientists. The systemic portrayal of the contemporary earth science knowledge was accompanied by an experiential engagement with life experiences of the seasonal cycles in a local context. This included the local micro-climates and the cultural histories of the area, reaching back to geological history and the rich capital of research on early hominids. Two notable areas here have been the Agulhas Bank and the Cradle of Humankind.

The historical evidence of early climate-related cultural mitigation and adaptation processes reviewed in this study are useful for contemplating climate change education as a more situated intergenerational and future-oriented process. This points to the need for a reduction in 'fearfactor' approaches to climate change education where the learning is better situated in African cultural histories and less centrally driven by abstract concepts and processes that are difficult to translate into material practices that are both practical and within reach. 


\section{Endnotes}

1. Climate scientist Dr George Philander pointed out to me how climate change is a science engaging complex uncertainties where its grasp of tangible effects sheds light on fluctuations and trends in seasonal cycles at global and regional levels. He thus proposed that we look into the cultural histories and seasonal cycles of Africa as a tangible way of working on the question of climate change for our education work in the southern African context.

\section{Notes on the contributor}

O’Donoghue, Rob

Environmental Learning Research Centre (ELRC), Rhodes University, South Africa r.odonoghue@ru.ac.za

Rob O'Donoghue is an Emeritus Professor at the ELRC at Rhodes University. In his research on environmental education processes of learning-led change, he has given close attention to indigenous knowledge practices, social theory and environmental learning in post-colonial curriculum and community contexts.

\section{References}

Denison, J. \& Wotshela, L. (2009). Indigenous water harvesting and conservation practices: Historical context, cases and implications. Water Research Commission project K5/1777//4, Report Number TT 392/09, April 2009.

Elias, N.J. (Trans.) (1993). Time: An essay. London: Blackwell.

Goudsbolom, J. (1989). Human history and social process. Exeter Studies in History no. 26. Exeter: University of Exeter Press.

Matthews, R.B., Holden S.T., Volk, J. \& Lungu, S. (1992). The potential of alley cropping in the improvement of cultivation systems in the high rainfall areas of Zambia I. Chitemene and Fundikila. Agroforestry Systems, 17, 219-240.

O’Donoghue, R.B., Kibuka-Sebitosi, E., Tshiningayamwe, S. \& Palmer, C. (2019). Navigating non-sense by exemplifying situated life experience and intergenerational heritage knowledge in Education for Sustainable Development learning spaces. South African Journal of Environmental Education, 35. DOI:10.4314/sajee.v35i1.8 